\title{
THE TWISTED CIRCULAR FORM OF POLYOMA VIRAL DNA*
}

\author{
By J. Vinograd, J. Lebowitz, R. Radloff, R. Watson, and P. Laipis \\ GATES AND CRELLIN LABORATORIES OF CHEMISTRY AND \\ THE NORMAN W. CHURCH LABORATORY OF CHEMICAL BIOLOGY, \\ CALIFORNIA INSTITUTE OF TECHNOLOGY \\ Communicated by Norman Davidson, March 30, 1965
}

The major part of the DNA from polyoma virus has been shown to consist of circular base-paired duplex molecules without chain ends. ${ }^{1-3}$ The intertwined circular form accounts for the ease of renaturation ${ }^{4}$ of this DNA and the failure of the strands to separate in strand-separating solvents. ${ }^{1-3}$

In previous studies ${ }^{1-3}$ a minor component, II, observed in variable amounts in sedimentation analyses of preparations of polyoma $\mathrm{DNA}$ at neutral $\mathrm{pH}$, was regarded to be a linear form of the viral DNA. Both the major component I (20S) and II (16S) were infective. ${ }^{1,5}$ In our further investigations of the minor component the following results, which are reported below, have been obtained: (1) The minor component is a ring-shaped duplex molecule. (2) It is generated by introducing one single-chain scission in component $I$ by the action of pancreatic DNAase or chemical-reducing agents. (3) The sedimentation coefficient of II is insensitive to several single-strand scissions. (4) The conversion products, when not excessively attacked, are infective.

The foregoing results raised a new problem. Why does the viral DNA, an intact duplex ring, sediment 20 per cent faster than a similar duplex ring containing one or more single-strand scissions? Experiments bearing on this problem, presented below, indicate the presence of a twisted circular structure in polyoma DNA I. A mechanism for the formation of this locked-in twisted structure is proposed.

Methods.-Isolation and purification of the virus and extraction of the DNA: Two methods, 7 for purification of the virus were used. The DNA was isolated by Weil's method ${ }^{4}$ except that the phenol was freshly distilled under argon.

Ultracentrifugation: Sedimentation analyses were performed in a Spinco model E ultracentrifuge by band centrifugation. ${ }^{8}$ Some of the results were recorded with the photoelectric scanning attachment. ${ }^{9}, 10$ Sucrose density gradient experiments were performed at $4^{\circ}, 30,000 \mathrm{rpm}$, and $9 \mathrm{hr}$. The $3 \%$ and $20 \%$ sucrose solutions contained SSC $(0.15 \mathrm{M} \mathrm{NaCl}$ and $0.015 \mathrm{M} \mathrm{Na}$ citrate) and $0.05 M$ Tris chloride $\mathrm{pH}$ 8.0.

Enzymes: Pancreatic DNAase, $1 \times$ crystallized, was obtained from Worthington Biochemicals Corp. E. coli endonuclease I, $1000 \mathrm{units} / \mathrm{ml},{ }^{11}$ and $E$. coli phosphodiesterase, $2000 \mathrm{units} / \mathrm{ml}^{12}$ were gifts from Professor I. R. Lehman. BSA, 30\% bovine albumin solution, sterile, was obtained from Armour Pharmaceutical Co. The endonuclease I, 0.12 units/ $\mu$ g DNA, converted $60 \%$ of I into linear molecules in $8 \mathrm{~min}$ at $20^{\circ}$ in the incubation mixture described by Lehman. ${ }^{11}$

Sedimentation velocity- $p H$ titration: Fifteen $\mu \mathrm{l}, 40 \mu \mathrm{g} / \mathrm{ml}$ DNA in SSC/10, flowed from the sample well of the type III ${ }^{13}$ band-forming centerpiece onto an alkaline $\mathrm{CsCl}$ bulk-solution. This solution was prepared by titrating $10 \mathrm{ml}$ (Harshaw Chemical Co.) optical grade $\mathrm{CsCl}, \rho=1.35$, with $1 M \mathrm{KOH}$ in $\mathrm{CsCl}, \rho=1.35$, at $20^{\circ}$ under argon, and was transferred to the cell assembly under argon. Usually four samples in a pH series were analyzed simultaneously. A Beckman research model pH meter, a general purpose probe glass electrode, and a calomel reference electrode modified with a ground glass junction ${ }^{14}$ were used.

Plaque assay: Infectivity of polyoma DNA was measured as described by Weil. ${ }^{4}$

Electron microscopy: Specimens were prepared by the method of Kleinschmidt and Zahn. ${ }^{15}$

Results.-Preparation of polyoma DNA II: Polyoma II can be prepared from I by treatment with several mild chemical-reducing agents (Table 1). These reagents 
TABLE 1

Action of Reducing Agents on Polyoma DNA

\begin{tabular}{|c|c|c|c|c|}
\hline Reagent & $M a$ & $\mathrm{pH}$ & $\begin{array}{l}\text { Time } \\
(\min )\end{array}$ & $\begin{array}{c}\text { Conversion }{ }^{b} \text { of } \\
\text { I to II }(\%)\end{array}$ \\
\hline Hydroquinone $^{c}$ & 0.0002 & 8.5 & 30 & 100 \\
\hline $\mathrm{FeCl}_{2}$ & 0.001 & 8.6 & 30 & 90 \\
\hline $\begin{array}{c}\mathrm{Na}_{2} \mathrm{SO}_{3}\left(1 \times 10^{-3} M\right. \\
\mathrm{Cu}_{2} \mathrm{SO}_{4}, 0.1 M \\
\left.\mathrm{NH}_{4} \mathrm{OH}\right)^{d}\end{array}$ & 0.01 & 10.8 & 60 & 45 \\
\hline Thiols ${ }^{\circ}$ & $0.01-0.02$ & $3.8-4.2$ & 60 & $80-90$ \\
\hline
\end{tabular}

$a$ Final concentration of reducing agents which were diluted fivefold with SSC/10, $0.01 M$ Tris $\mathrm{pH} 8.5$ containing $40 \mu \mathrm{g} / \mathrm{ml} \mathrm{DNA}$. The thiols were first dissolved in $0.4 M$ acetic acid before addition to the DNA containing $40 \mu \mathrm{g} / \mathrm{ml}$ DNA. The thiols were
solution.

${ }_{b}^{b}$ Sedimentation analysis at neutral $\mathrm{pH}$.

$c$ The reaction product was assayed for infectivity: $0.5 \times 10^{3} \mathrm{pfu} / \mu \mathrm{g}$ DNA compared with $1.5 \times 10^{3}$ obtained for untreated DNA in the same assay.

$d \mathrm{Cu}^{++}$acts as a catalyst. 16 In the absence of $\mathrm{Cu}^{++}$or $\mathrm{NH}_{4} \mathrm{OH} 5 \%$ conversion was observed. In the absence of $\mathrm{SO}_{3}-$ no conversion occurred.

e Mercaptoethanol, cysteine, and glutathione. In experiments with acetic acid without thiols, $10 \%$ conversion occurred.

were suggested by the observation that rigorous exclusion of impurities from the phenol, used in the isolation of the DNA, diminished the amount of the minor component II in the final DNA preparation. A simple conversion of I to II without intermediates and without detectable degradation products was observed in sedimentation analyses at pH 8.0 (Table 1). Based on the earlier assignment ${ }^{1,2}$ of a linear form to component II, the reactions with reducing agents and the infective nature of the products indicated a specific duplex cleavage. Dulbecco and Vogt ${ }^{1}$ reported a similar conversion of I to II with low concentrations of pancreatic DNAase. These authors postulated that a bond opposite the single-strand scission introduced by the enzyme hydrolyzed under the influence of ring strain. The foregoing puzzling results are clarified by the experiments below.

Structure of Polyoma II.-The products from the action of pancreatic DNAase and of the reducing agents (Table 1) were examined in the electron microscope. They were found to be in the circular form. Figure $1 b$ is typical of electron micrographs of materials obtained by treatment of I with pancreatic DNAase or with the several reducing agents. The possibility that linear molecules were selectively excluded in the preparation of the grids was eliminated by the results of a reconstruction experiment. A synthetic mixture of 10 per cent II and 90 per cent linear polyoma III (cf. below) showed the expected proportions of linear molecules.

The circular form for II is compatible with the proposal that the reducing agents and pancreatic DNAase introduce single-strand scissions into polyoma DNA I. It may be calculated that the circular form of the molecule should be retained until on the average about 50 single-strand scissions per molecule have been introduced. ${ }^{17}$ The material shown in Figure $1 b$ contained, on the average, about three breaks per molecule as calculated from the Poisson distribution.

A still milder treatment with pancreatic DNAase should give rise to singlestranded rings and uniform single-stranded linear molecules in strand-separating solvents, such as alkaline $\mathrm{NaCl}$ or $\mathrm{CsCl} .{ }^{2}, 18$ An example of such a result with 0.6 breaks per molecule is given in Figure $2 b$. These two components, $s^{\circ}{ }_{w, 20}=$ $18.4 \mathrm{~S} \pm 0.4,15.7 \mathrm{~S} \pm 0.3$ for the alkaline $\mathrm{Na} \mathrm{DNA}$, have been identified as singlestranded rings (18S) and single-stranded linear molecules (16S), respectively, by the following variation of an experiment originally performed with $\phi \mathrm{X}$ DNA by Fiers and Sinsheimer. ${ }^{19}$ An aliquot of the product of the pancreatic DNAase digestion 


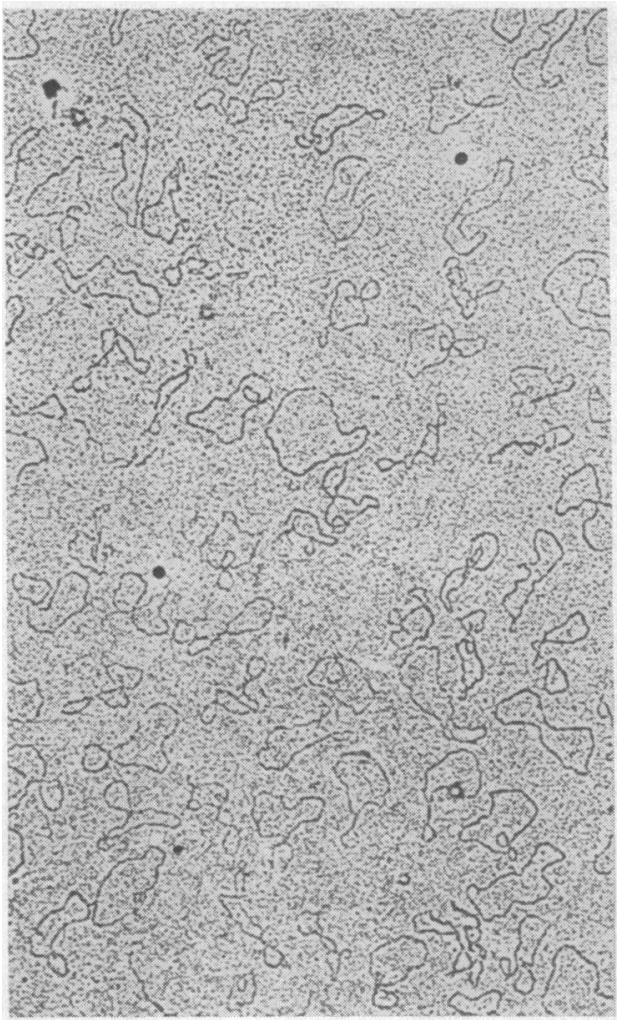

(a)

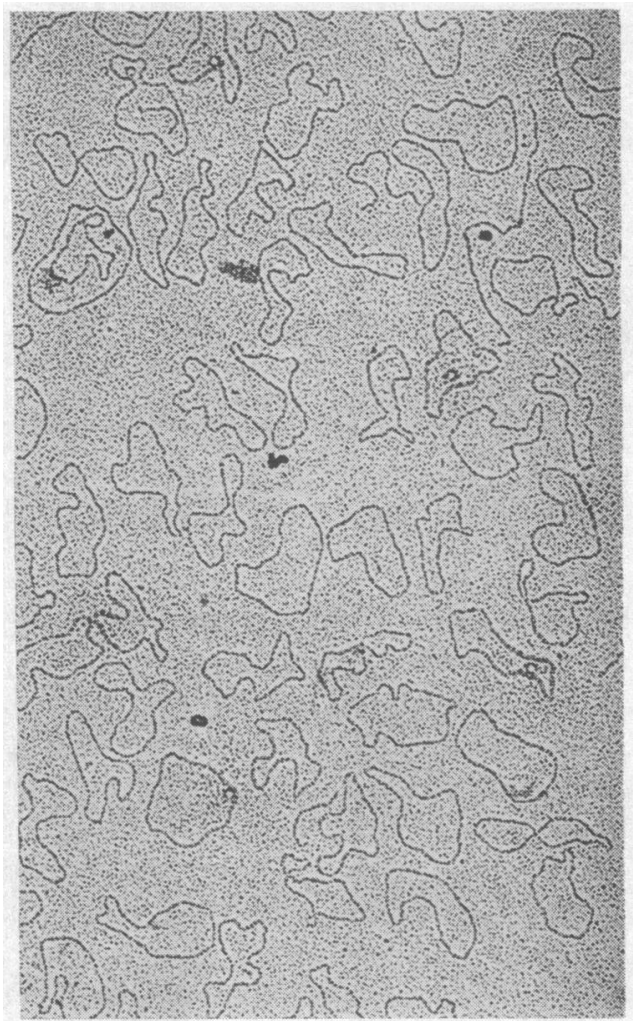

(b)

Fig. 1.-Electron micrographs of polyoma DNA $\times 21,000$. The materials in $(a)$ and $(b)$ were prepared by treatment of polyoma I with pancreatic DNAase, as described under Fig. 3. (a) was withdrawn from the reaction mixture after $5 \%$ conversion of I to II; (b) after $95 \%$ conversion.

( $40 \%$ conversion) was heat-denatured and treated with $E$. coli phosphodiesterase. This enzyme attacks single-stranded DNA with a free $3^{\prime} \mathrm{OH}$ group. It is seen that the amount of the $16 \mathrm{~S}$ component was substantially diminished, while the $18 \mathrm{~S}$ component was resistant to the exonuclease (Fig. 2c). Thus polyoma DNA II can contain a wholly intact circular strand. At this level of digestion the second strand in the molecule will contain only one or two breaks if the attack is statistical.

We now examine the possibility that one single-strand scission in the duplex is adequate to convert polyoma ring I to ring II. If only one-chain scission is necessary, the rate of conversion of I to II should be the same as the rate of conversion of the 53S component (intact, denatured, double-stranded, cyclic molecules) to the slower moving single-stranded molecules in alkali. If more than one break were necessary to convert I to II, a faster rate of conversion would be seen in alkali. Dulbecco and Vogt ${ }^{1}$ have already reported that the two rates are alike. In view of the importance of the result, we have repeated this experiment with the analyses performed in the analytical ultracentrifuge.

In Figure $3 a$ it is seen that the alkaline analyses and the neutral analyses give, within the experimental error, the same extent of conversion, a result which confirms the Dulbecco and Vogt finding. Therefore, the conversion of I to II occurs 


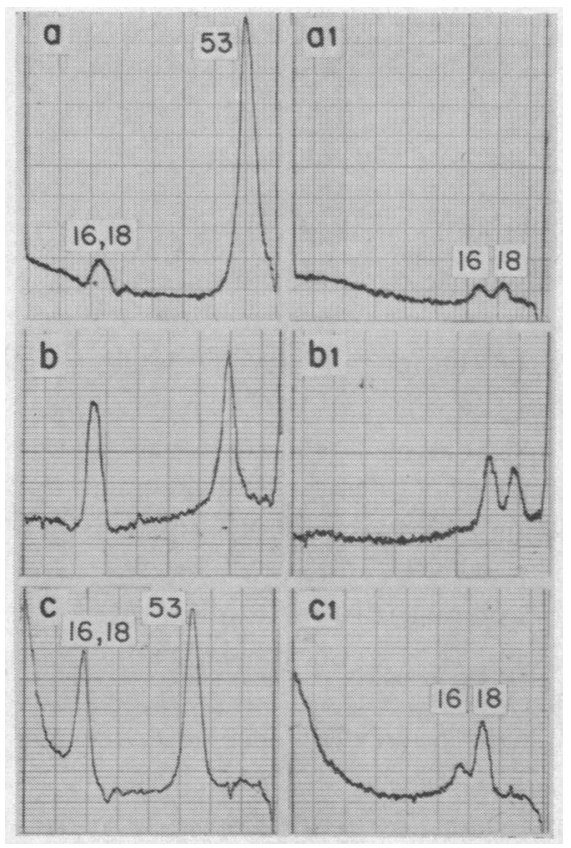

whenever the first single-strand scission is introduced. The conversion appears to be first order. While the infectivity (Fig. $3 b$ ) declines at a slower rate than the conversion of I to II, the scatter in the data precludes any conclusions regarding the kinetics of inactivation. It is clear, however, that the first single-strand scission in this duplex DNA is not lethal.

More extensive treatment with pancreatic DNAase or the chemicalreducing agents so as to completely convert I to II ( $>4$ average breaks per molecule) caused no detectable change in the sedimentation coefficient of II.

Preparation of Linear Polyoma DNA with E. coli Endonuclease I.Polyoma I was partially converted into the linear form with $E$. coli endonuclease $\mathrm{I}$, which is known to cleave duplex DNA. ${ }^{11}$ The sedimentation velocity of the homogeneous linear molecules was $14.5 \mathrm{~S}$
Fig. 2.-Sedimentation velocity patterns of polyoma DNA in alkaline $\mathrm{CsCl}$. The left and right patterns are scans at about $30 \mathrm{~min}$ and $90 \mathrm{~min}$ after sedimentation begins. The field is directed toward the right. $\mathrm{CsCl}, \rho=1.35 \mathrm{gm} \mathrm{cm}^{-3}, \mathrm{pH} 12.5$, 44,000 rpm. ( $a$, a1) Control: Component I isolated in a sucrose gradient experiment treated identically as in $(b)$ and $(c)$ except for the absence of enzymes and BSA. Separate experiments showed the BSA to be free of DNAase activity under the conditions used. $(b, b 1)$ Pancreatic DNAase treatment: $106 \mu \mathrm{g} / \mathrm{ml}$ pure I in $0.048 M$ $\mathrm{NaCl}, 0.0075 M \mathrm{MgCl}_{2}, 0.01 M$ Tris $\mathrm{pH} 8.0,40$ $\mu \mathrm{g} / \mathrm{ml} \mathrm{BSA}$, and $2.7 \times 10^{-4} \mu \mathrm{g} / \mathrm{ml}$ enzyme, $20 \mathrm{~min}$ at $20^{\circ}$. Reaction stopped by $1 / 15$ volume $1 M$ glycine buffer, $\mathrm{pH}$ 9.8. The leading band in $(a),(b)$, and $(c)$ is the $53 \mathrm{~S}$ component. The resolved slower bands in (a1), (b1), and (c1) are the $16 \mathrm{~S}$ and $18 \mathrm{~S}$ components. (c, c1) Effect of heat denaturation followed by $E$. coli phosphodiesterase treatment: Product of $(b)$ heated $5 \mathrm{~min} 100^{\circ}$, cooled rapidly. $70 \mu \mathrm{g} / \mathrm{ml}$ DNA in $0.03 M \mathrm{NaCl}, 0.005$ $M \mathrm{MgCl}_{2}, 0.007 M$ Tris, $0.067 M$ glycine $\mathrm{pH} 9.8$, $0.90 \mathrm{mg} / \mathrm{ml} \mathrm{BSA}, 71$ units $/ \mathrm{ml} E$. coli phosphodiesterase, $90 \mathrm{~min}$ at $37^{\circ}$. Reaction stopped by $1 / 10$ volume 0.1 $M$ EDTA.
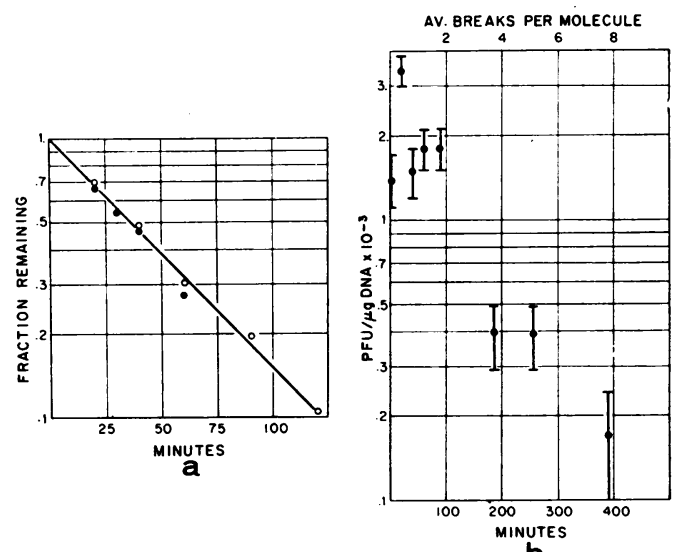

FIG. 3.-Chemical and biological effects of pancreatic DNAase treatment. (a) Analyses for single-stranded and double-stranded DNA. Extent of conversion was determined by band-sedimentation velocity experiments with photoelectric scanner. $\odot,(\mathrm{I}) /(\mathrm{I}+\mathrm{II})$ in neutral $\mathrm{CsCl}$ bulk solutions.,$(53 \mathrm{~S}) /($ total $)$ in alkaline $\mathrm{CsCl} \mathrm{pH}$ 12.3. Areas under bands were corrected for radial dilution. Incubation mixture and conditions were the same as those given in legend to Fig. $2 b$, except for enzyme concentration, $2.0 \times 10^{-4} \mu \mathrm{g} / \mathrm{ml}$. 20 $\mu l$ samples were withdrawn at the indicated times and added to $4 \mu \mathrm{l} 0.1 M$ EDTA $p H$ 8.5. The samples were frozen prior to analyses. (b) Infectivity of samples withdrawn from incubation in $(a)$. The time for a unit average number of hits was obtained from $(a)$ at $63 \%$ conversion. The error bars give the standard deviations from 16 replicate plates. 
at $\mathrm{pH}$ 8.0, the same as previously reported ${ }^{2}$ for the minor component III, and $16 \mathrm{~S}$ in alkali. Polyoma II was not produced in detectable amounts in the above conversion of I to linear molecules. Electron micrographs confirmed the assignment of a linear form to the enzymatic product and also to the minor component III isolated by sucrose gradient sedimentation.

Structure of Component I.-The high sedimentation coefficient of I relative to II indicates that the viral component is either more compact or larger in mass than the circular conversion product. In the extreme case of no increase in friction, a 20 per cent reduction in mass is required to account for the change in $s$. An equal amount of mass would have to have been lost as a result of the action of pancreatic DNAase and the variety of reducing agents used. An excision of viral DNA would have been detected by Dulbecco and Vogt, ${ }^{1}$ who were unable to find small fragments of labeled DNA after preparative band sedimentation of polyoma DNA treated with

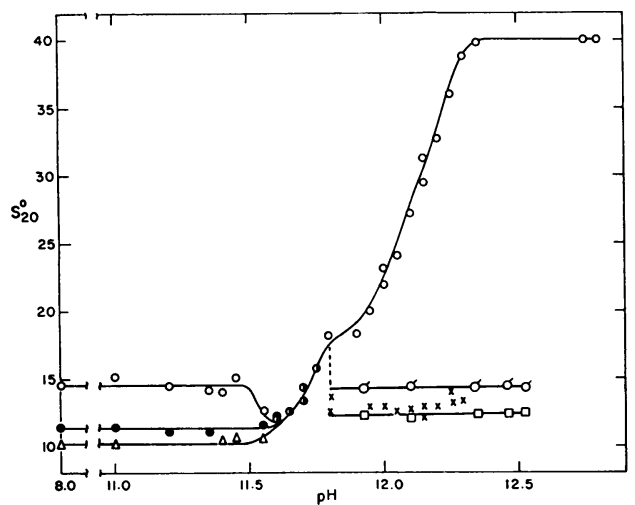

FIG. 4.- Sedimentation velocity-pH titration of the three components in polyoma DNA. I, O; II, O; III, $\triangle$; $O$ only band present, ef. text; mixture of unresolved single strands in alkali, x; 29,500 rpm. Single linear, $\square$, and single circular, $\sigma$, strands in alkali, 44,770 rpm. Sedimentation coefficients at $20^{\circ}$ in $\mathrm{CsCl}, \rho=1.35 \mathrm{gm} \mathrm{cm}^{-3}$, are not corrected for solvent viscosity, $\eta_{\mathrm{r}}=0.925$, or buoyancy effects. The values at $\mathrm{pH} 8.0$ and 12.4 are the means of 12 and 7 determinations, respectively.

(2) A study of the sedimentation velocity in $3 \mathrm{M} \mathrm{CsCl}$ of a mixture of the three components of polyoma DNA as a function of $\mathrm{pH}$ from 8 to 12.5 revealed a complicated pH-melting curve for component I (Fig. 4). Component II behaved normally ${ }^{18,},{ }^{20}$ and moved faster as denaturation increased until strand separation occurred with an attendant sudden drop in sedimentation velocity at $\mathrm{pH} 11.8$. Component I, like II, was at first insensitive to $\mathrm{pH}$. At pH 11.5, however, the sedimentation coefficient first dropped, and then in the $\mathrm{pH}$ range 11.6 to 11.8 was the same as for polyoma II. Only one moving band was observed in this $\mathrm{pH}$ range. The sedimentation coefficient of I then increased to the very high value characteristic of the double-stranded cyclic coil previously reported. ${ }^{2}$ Essentially the same results were obtained in $1.0 \mathrm{M} \mathrm{KCl}$ solutions. The dip in the sedimentation velocity- 
$\mathrm{pH}$ curve was initially unexplainable. If, however, polyoma DNA I contains lefthanded tertiary turns, such a dip in the $\mathrm{pH}$-melting profile would be required. In the early stages of denaturation some of the duplex turns, which are known to be right-handed, unwind. The unwinding of the duplex must be accompanied by a right-handed twisting of the remainder of the molecule. If the tertiary turns were originally left-handed (Fig. 5), progressive unwinding would cause the molecule to pass through configuration $I^{\prime}$ characterized by the absence of tertiary turns. The extended configuration $I^{\prime}$ is similar to that in polyoma II (Fig. 5) and both $I^{\prime}$ and II would have similar sedimentation velocities. Further unwinding of duplex $I^{\prime}$ is accompanied by continued right-hand twisting of the whole molecule until finally the double-stranded cyclic coil $^{2}$ configuration develops.

(3) The twisted circular structure provides a satisfactory explanation for the configurational change that occurs when one single-strand scission is introduced into the molecule. Such a scission generates a site for the rotation of the helix in the complementary strand opposite the break. The swivel relieves the topological restraint responsible for the twisted configuration.

Discussion.-A mechanism for the formation of the twisted circular structures suggested by the above analysis of the $\mathrm{pH}-$ melting curve. According to this mechanism the last closure of chain ends occurs before all of the winding of the two DNA strands into the Watson-Crick structure is completed. The closing leaves the duplex in the configuration $\mathrm{I}^{\prime}$ (Fig. 5) restrained from converting to $I$ by an as yet unknown factor participating in the DNA synthesis. Removal of the restraint then allows $I^{\prime}$ to wind spontaneously into a complete Watson-Crick structure and form the twisted circular structure, I, with

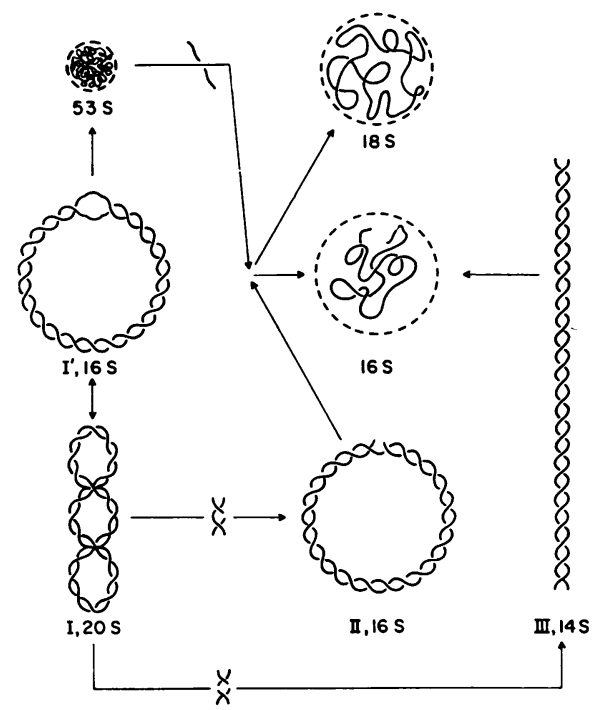

Fig. 5.-Diagrammatic representation of the several forms of polyoma DNA. The duplex segments shown contain 12 turns, about one fortieth of the total number. The twisted circular duplex shown contains one left-hand tertiary turn. $8 \%$ of the righthand duplex turns in the model are unwound to form $I^{\prime}$. The dashed circles around the denatured forms indicate the relative hydrodynamic diameters. The sedimentation coefficients were measured in neutral and alkaline $\mathrm{NaCl}$ solutions. no change in winding number.

An alternative proposal is that the molecule in form II, which contains a swivel, is twisted by some organizer, e.g., the virus protein. The last covalent backbone bond is then made while the DNA remains twisted under the constraint of the organizer. This alternative is unlikely in view of Dulbecco's ${ }^{21}$ finding that the polyoma DNA made before virus production begins has the sedimentation velocity of component $\mathrm{I}$.

It is not possible at the present time to estimate reliably the number of tertiary turns. A turn is defined as a $360^{\circ}$ rotation of the helix. The electron micrographs of I usually contain some molecules that are completely extended; these 
may have suffered a single break during grid preparation or may have been in state $\mathrm{I}^{\prime}$ due to denaturation induced by the spreading forces. This latter action would result in the unwinding of the twisted circles to form extended circles. The maximum number of crossovers that can be distinguished is 8 , which corresponds to 4 turns or the unwinding of 40 base pairs. This limit may be low because it is difficult to count crossovers in tightly coiled forms. That the number of tertiary turns in the molecule is not large is suggested by the fact that the transition of $I$ to I' occurs before substantial melting of II takes place, as indicated by the $s$ versus $\mathrm{pH}$ plot.

With the new assignment of structure to the three components of polyoma DNA, it is found that satisfactory agreement obtains between the observed sedimentation coefficient of the linear form, $14.5 \mathrm{~S}$, and the $15.3 \pm 0.5 \mathrm{~S}$ predicted by Studier's relation $^{18}$ for a molecular weight ${ }^{2}$ of $3.0 \pm 0.3 \times 10^{6}$. The values, $18.4 \mathrm{~S}$ and 15.7S for the alkaline single-stranded circular and linear forms similarly agree with the predicted values of $17.4 \mathrm{~S}$ and $15.6 \mathrm{~S}$, respectively. The effect of ring closure of III to form component II is to increase $\mathrm{S}$ by 10 per cent. An effect of similar magnitude has been reported ${ }^{22}$ for the cyclization of $\lambda$ DNA.

The twisted circular structure observed here for polyoma DNA may be a common characteristic of covalently closed, circular duplex DNA. A part of the DNA from rabbit papilloma virus, ${ }^{23} \mathrm{SV} 40$ virus, ${ }^{3}$ and the replicating form of $\phi \mathrm{X} \mathrm{DNA}{ }^{24-26}$ have all been shown to be circular duplex molecules which do not strand-separate in alkali or after heating in formaldehyde. Two sedimentation velocity components differing by 20-30 per cent have been reported for the above DNA's. ${ }^{27}$ Crawford and Black $^{3}$ observed sedimentation velocity-denaturation curves that are similar to our pH-melting curve upon heating SV40 DNA and polyoma DNA in formaldehyde solutions to various temperatures. No explanation was offered for this behavior, which we interpret as indicating the presence of a left-handed, twisted circular structure. $^{28}$

Burton and Sinsheimer ${ }^{29}$ have shown that the slow component II in RF- $\phi \mathrm{X}$ DNA dissociates in alkali to form linear and circular single-stranded molecules and have concluded that both of the undenatured forms of the DNA are circular. While this communication was in preparation, Jansz and Pouwels ${ }^{30}$ reported that the pancreatic DNAase-induced conversion of I to II in RF- $\phi$ X DNA represents a conversion between circular duplex molecules. No explanation for the change in the sedimentation coefficient was offered. In view of the results described here, it is likely that $\mathrm{RF}-\phi \mathrm{X}$ DNA is in the twisted circular form. A common mechanism for the incorporation of the tertiary turns during replication is a strong possibility, and allows us to predict that the tertiary turns in the RF- $\phi$ X DNA will be found to be left-handed.

Summary.-The results of this study show that circular duplex polyoma DNA may be converted to a less compact circular duplex by introducing a single-strand scission. The viral form contains tertiary turns which appear to have been locked in during replication.

It is a pleasure to thank I. R. Lehman for the generous gift of the $E$. coli enzymes, R. L. Sinsheimer, J. Petruska, and M. Fried for helpful discussions, R. Dulbecco for allowing us to quote his unpublished results, and T. Benjamin, L. Wenzel, and A. Drew for advice and assistance in the culture of the virus and the assay of the DNA. This work was supported in part by grants HE 03394 and CA 08014 from the U.S. Public Health Service. 
* This work was reported in part at the 9th Annual Meeting of the Biophysical Society, February 24, 1965. Contribution 3227 of Gates and Crellin Laboratories of Chemistry.

1 Dulbecco, R., and M. Vogt, these Procendings, 50, 236 (1963).

${ }^{2}$ Weil, R., and J. Vinograd, these Proceedings, 50, 730 (1963).

${ }^{3}$ Crawford, L. V., and P. H. Black, Virology, 24, 388 (1964).

${ }^{4}$ Weil, R., these Proceedings, 49, 480 (1963).

${ }^{5}$ Crawford, L. V., R. Dulbecco, M. Fried, L. Montagnier, and M. Stoker, these Proceedings, 5z, 148 (1964).

${ }^{6}$ Winocour, E., Virology, 19, 158 (1963).

"Murikami, W., Science, 142, 56 (1963).

$\checkmark$ Vinograd, J., R. Bruner, R. Kent, and J. Weigle, these Proceedings, 49, 902 (1963).

9 Beckman Instruments Co., Spinco Division, Palo Alto, Calif.

${ }^{10}$ Hanlon, S., K. Lamers, G. Lauterbach, R. Johnson, and H. K. Schachman, Arch. Biochem. Biophys., 99, 157 (1962).

${ }^{11}$ Lehman, I. R., G. G. Roussos, and E. A. Pratt, J. Biol. Chem., 237, 819 (1962).

12 Lehman, I. R., J. Biol. Chem., 235, 1479 (1960).

13 Vinograd, J., R. Radloff, and R. Bruner, Biopolymers, in press.

${ }^{14}$ Lebowitz, J., and M. Laskowski, Jr., Biochemistry, 1, 1044 (1962).

${ }^{15}$ Kleinschmidt, A. K., and R. K. Zahn, Z. Naturforsch., 14b, 770 (1959).

${ }^{16}$ Swan, J. M., Nature, 180, 643 (1957).

${ }^{17}$ Thomas, C. A., Jr., J. Am. Chem. Soc., 78, 1861 (1956). The estimate of 50 was obtained for the case of a $10 \%$ lowering of the weight average molecular weight.

18 Studier, F. Wm., J. Mol. Biol., 11, 373 (1965).

${ }^{19}$ Fiers, W., and R. L. Sinsheimer, J. Mol. Biol., 5, 408 (1962).

${ }^{20}$ Davidson, P. F., and D. Freifelder, J. Mol. Biol., 5, 643 (1962).

${ }^{21}$ Dulbecco, R., private communication.

22 Hershey, A. D., E. Burgi, and L. Ingraham, these Proceedings, 49, 748 (1963).

${ }^{23}$ Crawford, L. V., J. Mol. Biol., 8, 489 (1964).

24 Kleinschmidt, A., A. Burton, and R. L. Sinsheimer, Science, 142, 961 (1963).

${ }^{25}$ Burton, A., and R. L. Sinsheimer, Science, 142, 962 (1963).

${ }^{26}$ Burton, A., and R. L. Sinsheimer, Abstracts, 8th Annual Meeting of the Biophysical Society, 1964.

${ }^{27} \mathrm{R}$. Weil has informed us that the slow component II in rabbit papilloma DNA is circular as seen in the electron microscope.

${ }^{28}$ Human papilloma DNA appears to be similar in configuration to SV40 DNA and polyoma DNA (Crawford, L. V., manuscript submitted for publication).

${ }^{29}$ Burton, A., and R. L. Sinsheimer, private communication.

${ }^{30}$ Jansz, H. S., and P. H. Pouwels, Biochem. Biophys. Res. Commun., 18, 589 (1965).

\title{
PYRIMIDINE DIMERS IN UV-IRRADIATED POLY dI:dC*
}

\author{
By R. B. Setlow, W. L. Carrier, and F. J. Bollum
}

BIOLOGY DIVISION, OAK RIDGE NATIONAL LABORATORY, OAK RIDGE, TENNESSEE

Communicated by Alexander Hollaender, March 29, 1965

Ultraviolet irradiation of polynucleotides containing thymine results in the formation of dimers between adjacent thymine residues. ${ }^{1,2}$ The demonstration that these dimers are responsible to a large, but not exclusive, extent for the inactivation of primer $\mathrm{DNA}^{3}$ and of transforming $\mathrm{DNA}^{4}$ made use of a specific photochemical property of the dimers, namely, that they may be monomerized by short-wavelength irradiation. The fact that many UV effects are photoreactivable and that treat- 